\title{
Patient selection could be the Holy Grail of thoracic endovascular aortic repair for chronic dissecting aneurysm
}

\author{
Ourania Preventza, MD, ${ }^{\mathrm{a}, \mathrm{b}}$ and Peter Chen, $\mathrm{MD}^{\mathrm{b}}$
}

\footnotetext{
From the ${ }^{\mathrm{a} D e p a r t m e n t}$ of Cardiovascular Surgery, Texas Heart Institute, Houston, Tex; and ${ }^{\mathrm{b}}$ Division of Cardiothoracic Surgery, Baylor College of Medicine, Houston, Tex.

Disclosures: Authors have nothing to disclose with regard to commercial support.

Received for publication March 16, 2018; accepted for publication March 21, 2018; available ahead of print April 14, 2018.

Address for reprints: Ourania Preventza, MD, Division of Cardiothoracic Surgery, Baylor College of Medicine, Department of Cardiovascular Surgery, Texas Heart Institute, 6770 Bertner Ave, Houston, TX 77030 (E-mail: opsmile01@aol.com).

J Thorac Cardiovasc Surg 2018;156:36-7

$0022-5223 / \$ 36.00$

Copyright (c) 2018 by The American Association for Thoracic Surgery

https://doi.org/10.1016/j.jtcvs.2018.03.074
}

Debate is ongoing about how best to manage aneurysms associated with chronic Type IIIb aortic dissection. For chronic dissecting thoracoabdominal aortic aneurysm (TAAA) resulting from chronic Type I or Type III aortic dissection, the gold standard remains open surgical repair. ${ }^{1}$ In addition, the number of dissecting TAAAs that are repaired with a total endovascular procedure is lower than the number of TAAAs without dissection, and these procedures are performed at few centers. With the promising findings of aortic remodeling and decreased mortality in patients with chronic distal aortic dissection in the Investigation of Stent Grafts in Aortic Dissection trial, ${ }^{2}$ more thoracic endovascular aortic repairs (TEVARs) are being performed in patients with chronic dissecting TAAA. However, studies to date have not concentrated on the fate of the abdominal aorta after the stented area of the thoracic aorta remodels or how these patients perform long term.

In this elegant report, Kim and colleagues ${ }^{3}$ from Yonsei University College in Seoul, Korea, draw 2 important conclusions. First, remodeling of the stented descending thoracic aorta with complete or incomplete thrombosis of the false lumen (FL) has no effect on the outcome of residual abdominal aortic dissection. Some would expect that because of the different pressures that arise in the FL with complete and incomplete thrombosis, the abdominal expansion should be related to the thrombosis of the FL of the stented segment, which is not the case. Second, as was somewhat expected, large intimal tears and total reentries were anatomic risk factors for abdominal aneurysmal change. In the results of the Investigation of Stent Grafts in Aortic Dissection trial, we thought we had found the Holy Grail, and we may have, in part. In their study, Kim and colleagues ${ }^{3}$ showed that during follow-up, only 3 of 70 patients underwent abdominal aortic FL

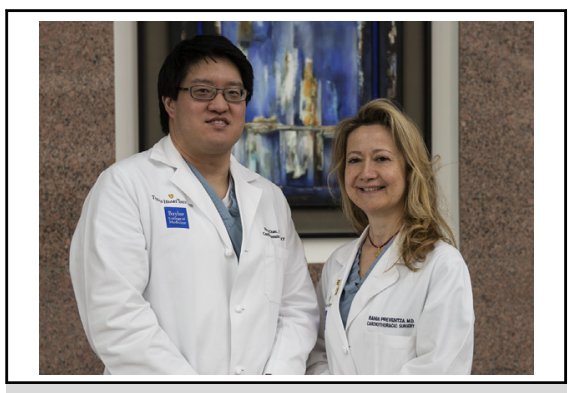

Dr Preventza is proud to coauthor this editorial with chief resident Peter Chen.

Central Message

Although TEVAR in chronic dissecting aneurysm is not the Holy Grail yet, careful patient selection and various false-lumen procedures could improve results. Long-term follow-up is imperative.

See Article page 27. procedures, which is promising. One could argue that even if the abdominal component around the visceral vessels will eventually require another endovascular procedure or even an open operation, this can be a lesser procedure than replacing the entire thoracoabdominal aorta in an open operation as long as the thoracic part is remodeled. This certainly applies to older patients. We should be more cautious with younger patients, who may benefit more from an open operation with a definitive repair than a "lesser fix" that necessitates multiple secondary endovascular interventions, intraoperative radiation exposure, and postoperative radiation exposure due to vigorous computed tomography surveillance.

Patient selection and the timing of potential procedures may be the key. Patients with fewer tears and longer distance between the tears, which can decrease the wall shear stress contributing to the thrombosis, may be better candidates. Also, a TEVAR followed shortly by an additional FL procedure in the abdominal component could treat the entire TAAA while avoiding extensive open procedures. Long-term data collection is imperative as we try to decide the best approach.

In addition, post-TEVAR remodeling happens faster in acute dissection than in chronic dissection. This suggests that the plasticity of the aorta in the acute phase opens a 
great potential therapeutic window for endovascular treatment, which could lead to fewer patients requiring treatment in the chronic phase.

\section{References}

1. Preventza O, Price MD, Amarasekara HS, Tullos A, Chen P, Reidy MR, et al. Chronic Type I and Type III aortic dissections: a propensity analysis of outcomes after open distal repair. Eur J Cardiothorac Surg. March 2, 2018 [Epub ahead of print].

2. Nienaber CA, Kische S, Rousseau H, Eggebrecht H, Rehders TC, Kundt G, et al Endovascular repair of type B aortic dissection: long-term results of the randomized investigation of stent grafts in aortic dissection trial. Circ Cardiovasc Interv. 2013;6:407-16.

3. Kim T-H, Song S-W, Lee K-H, Baek M-Y, Yoo K-J, Lee HS. Fate of the abdominal aorta after endovascular treatment in chronic Debakey IIIb aneurysm. J Thorac Cardiovasc Surg. 2018;156:27-35.e1. 